\title{
A comparison of two different dosages of somatostatin combined with sclerotherapy for the treatment of acute esophageal variceal bleeding: a prospective randomized trial
}

\author{
J. M. Palazón, J. Such, J. Sánchez-Payá1 ${ }^{1}$ L. Company, E. de Madaria, L. Sempere², J. Martínez², \\ P. Zapater ${ }^{3}$, S. Pascual, F. Carnicer and M. Pérez-Mateo \\ Liver Unit. ${ }^{1}$ Departments of Epidemiology, ${ }^{2}$ Gastroenterology and ${ }^{3}$ Clinical Pharmacology. Hospital General \\ Universitario. Alicante, Spain
}

\begin{abstract}
Background: the association of somatostatin (SMT) with endoscopic therapy in patients with cirrhosis and variceal bleeding significantly improves the control of the bleeding episode, and hemodynamic data have shown that a dosage of $500 \mu \mathrm{g} / \mathrm{h}$ allows a more marked reduction of portal pressure versus the usual dosage of $250 \mu \mathrm{g} / \mathrm{h}$.

Aim: to assess if the $500 \mu \mathrm{g} / \mathrm{h}$ dosage is associated with an improved outcome.

Methods: sixty-two patients with variceal bleeding were included in the study. Patients were randomized to receive the usual dosage of SMT (group I: $250 \mu \mathrm{g} / \mathrm{h}$ ), or a double dosage (group II: $500 \mu \mathrm{g} / \mathrm{h}$ ), together with emergency endoscopic sclerotherapy.

Results: the control of the bleeding episode was similar in both groups of patients. Early rebleeding was less frequent in patients receiving double vs. single dosage of SMT $(p=0.06)$. When considering patients with advanced liver disease (Child-Pugh B or C) early rebleeding was significantly less frequent in patients receiving the $500 \mu \mathrm{g} / \mathrm{h}$ dose of SMT (39 vs. 13\%, p = 0.03).

Conclusions: the perfusion of higher doses of SMT (500 $\mu \mathrm{g} / \mathrm{h}$ ) in association with emergency sclerotherapy in patients with cirrhosis and esophageal hemorrhage significantly decreases the rate of early rebleeding in patients with more advanced stages of liver disease.
\end{abstract}

Key words: Cirrhosis. Portal hypertension. Somatostatin. Variceal bleeding.

Palazón JM, Such J, Sánchez-Payá J, Company L, de Madaria E, Sempere L, Martínez J, Zapater P, Pascual S, Carnicer F, Pérez-Mateo M. A comparison of two different dosages of somatostatin combined with sclerotherapy for the treatment of acute esophageal variceal bleeding: a prospective randomized trial. Rev Esp Enferm Dig 2006; 98: 249-254.

Recibido: 12-09-05.

Aceptado: 08-03-06.

Correspondencia: José M. Palazon. Liver Unit. Hospital General Universitario. C/ Pintor Baeza, s/n. 03010 Alicante. Fax: 965938 355. e-mail: palazon_jma@gva.es.

\section{INTRODUCTION}

Portal hypertension is the most frequent complication in patients with cirrhosis, and portal hypertension-related bleeding is the cause of death in roughly $20 \%$ of cases (1). Routine therapy of esophageal variceal bleeding includes endoscopic therapy together with hemodynamic stabilization and a prophylaxis of encephalopathy and bacterial infection (2). An association of vasoactive drugs with endoscopic procedures, and prolonged therapy for 2 to 5 days to decrease short-term rebleeding is recommended (3).

Somatostatin (SMT) is a vasoactive drug that has been widely used during at least two decades (4) in the treatment of acute variceal bleeding due to its capacity to decrease portal pressure with none of the adverse effects commonly observed with other drugs such as vasopressin on the systemic circulation (5). In cirrhotic patients with acute variceal bleeding, somatostatin induces a significant and sustained decrease in the hepatic venous pressure gradient (6). The intravenous administration of a bolus of SMT induces a rapid and marked decrease of portal pressure, which is less evident during chronic perfusion (7). Similar results have been observed with direct measurements of variceal pressure (8). A dosage of $500 \mu \mathrm{g} / \mathrm{h}$ allows a more marked reduction of portal pressure than a dosage of $250 \mu \mathrm{g} / \mathrm{h}(7)$.

While placebo-controlled trials demonstrated no beneficial effects of SMT on bleeding control or survival in patients with variceal hemorrhage (9), the fact that SMT efficacy in the control of bleeding episodes has been shown to be similar to that of endoscopic sclerotherapy and terlipressin indirectly supports the beneficial effects of SMT (10). In a prospective randomized trial, a dosage of 500 $\mu \mathrm{g} / \mathrm{h}$ has been shown to be more efficacious than the usual dosage of $250 \mu \mathrm{g} / \mathrm{h}$ in patients with active bleeding (11). Furthermore, a previous non-randomized study had shown that the association of $500 \mu \mathrm{g} / \mathrm{h}$ with endoscopic banding 
reduces active bleeding during endoscopy, as well as transfusion requirements (12). These data have induced the recommendation of administering a dosage of $250-500 \mu \mathrm{g} / \mathrm{h}$ in patients with acute variceal bleeding (13). No randomized controlled trials, however, have addressed which is the adequate dosage for SMT infusions in association with emergency sclerotherapy in patients with variceal bleeding.

The aim of this prospective, open, randomized trial was therefore to compare the efficacy of treatment using two different SMT dosages $(250 v s .500 \mu \mathrm{g} / \mathrm{h})$ in association with emergency endoscopic sclerotherapy in patients with esophageal variceal bleeding.

\section{PATIENTS AND METHODS}

\section{Study design}

During the study period all patients with cirrhosis and esophageal variceal bleeding were included in this prospective, open, randomized trial. Cirrhosis was diagnosed by histology or by clinical, laboratory, and/or ultrasonographic findings. The Hospital General Universitario de Alicante Ethics Committee approved the study protocol, and all patients gave their informed consent for their inclusion in the study.

Inclusion criteria included the endoscopic demonstration of active bleeding from esophageal varices or stigmata of recent hemorrhage and bright red blood in the gastric aspirate with no other source of bleeding in the emergency endoscopy. Exclusion criteria were a previous assignation to any clinical trial or endoscopic therapy for esophageal varices over the previous month, portal hypertension of non-cirrhotic origin, portal vein thrombosis, shunt operations or transjugular intrahepatic portosystemic shunt (TIPS), age $\leq 18$ or $\geq 80$ years, pregnancy, presence of multinodular hepatocellular carcinoma or a single nodule larger than $5 \mathrm{~cm}$ in diameter, hipersensitivity to any component of the somatostatin formulation, and presence of type-I hepatorenal syndrome (14).

\section{Selection of patients}

From December 1998 to December 2000 all patients admitted to the Bleeding Unit of Hospital General Universitario de Alicante with upper gastrointestinal bleeding of variceal origin who fulfilled both inclusion and exclusion criteria as defined above were considered for inclusion in this study.

\section{Randomization and treatment}

After admission, the staff evaluated all patients. According to patient characteristics, past history and preliminary laboratory study, once a suspicion of esophageal variceal bleeding was established, and after obtaining a written permission from the patient or his/her relatives, patients were randomly assigned to the following therapeutic groups by means of sealed, opaque envelopes containing each treatment option, as derived from computergenerated random numbers:

Group I: initial administration of a bolus of SMT 250 $\mu \mathrm{g}$, followed by endoscopic injection sclerotherapy and a continuous perfusion of SMT $250 \mu \mathrm{g} / \mathrm{h}$ for 5 days.

Group II: initial administration of a bolus of SMT 500 $\mu \mathrm{g}$, followed by endoscopic injection sclerotherapy and a continuous perfusion of SMT $500 \mu \mathrm{g} / \mathrm{h}$ for 5 days.

Immediately following the administration of the SMT bolus, trained staff performed an upper endoscopy on all patients within 2 hours of patient admission. All patients included in the study received an intravariceal or paravariceal injection of 5\% ethanolamine oleate, $1-2 \mathrm{ml}$ in each varix from the cardia to the proximal esophagus including the rupture point, if identified. The maximal volume of sclerosing agent allowed was $20 \mathrm{ml}$. Two patients in each therapeutic group were excluded after randomization because a non-variceal origin for bleeding was observed (3 duodenal ulcers, 1 Mallory-Weiss syndrome) during the initial endoscopy.

All patients admitted to our Bleeding Unit were closely monitored and received supportive care for hemodynamic resuscitation. A nasogastric tube was passed, and lavages were regularly performed to allow fresh blood and clot removal in order to facilitate endoscopy and to decrease the risk of massive aspiration and/or encephalopathy. The usual clinical parameters were electronically recorded (blood pressure, heart rate, temperature) together with urine output. A central venous pressure catheter was set in place when needed to avoid volume overload during intravascular volume restoration. Hemoglobin concentration was measured at least daily or when clinically required. Blood transfusions were administered to maintain hemodynamic stability and/or hemoglobin levels around $9 \mathrm{~g} / \mathrm{dL}$. All patients received norfloxacin $400 \mathrm{mg}$ BID for 7 to 10 days to prevent bacterial infection (2). Plasma glucose levels were measured every 8 hours, and liver function tests were performed daily during the first 5 days. Portal vein patency was assessed in the early hours after admission by means of doppler ultrasounds.

In patients with continuous or recidivant bleeding despite initial therapy, different approaches were considered: increased SMT dosage to $500 \mu \mathrm{g} / \mathrm{h}$, second therapeutic endoscopy or TIPS in selected cases. After completing the study period patients were treated with either propranolol or variceal banding, according to patient inclusion in other therapeutic trials of secondary prophylaxis for variceal bleeding.

\section{Endpoint definitions}

Failure criteria included the presence of hematemesis or fresh blood in nasogastric aspirates with signs of 
hypovolemia (systolic blood pressure $<100 \mathrm{mmHg}$, heart rate $>100$ beats/min) or the need for two or more units of packed red cells to keep hemoglobin around $9 \mathrm{~g} / \mathrm{dl}$ (3). Initial hemostasis was defined when failure criteria did not occur within 24 hour after initial endoscopy. Early rebleeding was defined when failure criteria occurred beyond 24 hours from the initial control visit and within the first 5 days. Efficacy of treatment was established when a patient presented initial hemostasis and not early rebleeding. Mortality was defined as any death within 6 weeks after randomization (3). Any drug therapy- or endoscopy-related adverse effects were recorded. Patients with persistent thoracic pain were re-endoscoped 48 hours after initial endoscopy and sclerotherapy.

\section{Sample size calculation}

According to a single therapeutic trial that had been published before 1998 comparing sclerotherapy associated with SMT in a dosage of $250 \mu \mathrm{g}$ versus sclerotherapy alone (15), sample size calculation was performed assuming a therapeutic success rate in controlling variceal bleed for 5 days of $65 \%$ for patients treated with urgent sclerotherapy and SMT $250 \mu \mathrm{g}$. Thirty-one patients were required in each group to detect differences above $25 \%$, assuming an $\alpha$ of $5 \%$ and $\beta$ of $20 \%$, in a one-tail comparison. The selection of one-tail was made because results were only probable and interesting in a positive direction.

\section{Statistical analysis}

Data evaluation was performed using an intention-totreat strategy. Data are presented as means \pm SD for quantitative variables, and as absolute and relative frequencies for qualitative variables. The homogeneity for variables such as age, sex, etiology of cirrhosis, ChildPugh score, hemoglobin at admission, and presence of active bleeding at initial endoscopy was assessed. Fisher's exact probability test was used to study the association between therapeutic group and therapy efficacy, mortality or presence of complications, and according to a directional hypothesis we considered a $\mathrm{p}$ one-tailed value of less than 0.05 as significant. Relative risk (RR) and 95\% confidence intervals, relative risk reduction (RRR) attributable to treatment in the exposed group, and number needed to treat (NNT) were all calculated to assess association size. RRR is based on the formula: RRR = (RR-1)/RR. NNT was defined as the number of patients that must be treated in order to avoid one episode of variceal rebleeding or death in patients of group II, NNT $=1 /$ difference in proportions. The Mann-Whitney U test was used to assess the effect of therapy on the number of packed red cells administered or hospitalization length.

\section{RESULTS}

\section{Patient characteristics}

Overall 62 patients were included in this study -29 received SMT at usual doses of $250 \mu \mathrm{g}$ and were included in group I and 33 received $500 \mu \mathrm{g}$ of SMT and were included in group II (Fig. 1). Mean age of patients included in group II was significantly higher versus group I. The remaining clinical characteristics of both groups were similar at inclusion (Table I).

\section{Bleeding control}

The rate of initial hemostasis was similar in both groups of patients $(90 \%$ [26/29] vs. 85\% [28/33] $\mathrm{p}=0.43$; RR 0.9 [0.7-1.1]) in groups I and II, respectively. Early

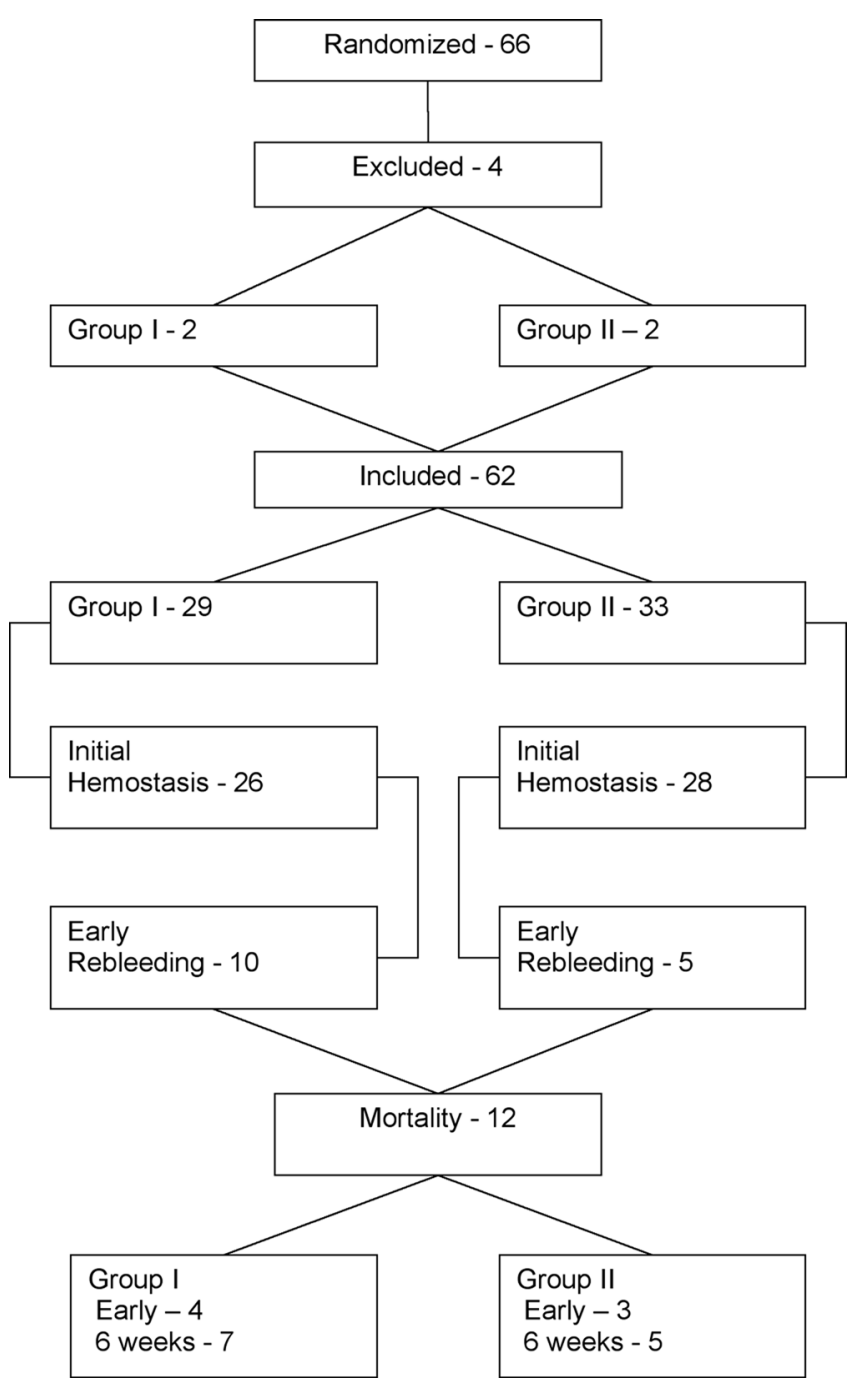

Fig. 1.- Flow diagram of subject progression through the study. 
Table I. Characteristics of patients at admission

\begin{tabular}{|c|c|c|c|}
\hline & $\begin{array}{l}\text { Group I } \\
(n=29)\end{array}$ & $\begin{array}{l}\text { Group II } \\
(n=33)\end{array}$ & $p$ \\
\hline Agea & $50 \pm 11$ & $57 \pm 12$ & 0.01 \\
\hline $\begin{array}{l}\text { Sex } \\
\text { Male } \\
\text { Female }\end{array}$ & $\begin{array}{c}26(89.7 \%) \\
3(10.3 \%)\end{array}$ & $\begin{array}{c}26(78.8 \%) \\
7(21.2 \%)\end{array}$ & 0.41 \\
\hline $\begin{array}{l}\text { Etiology } \\
\text { Alcoholic } \\
\text { Non-alcoholic }\end{array}$ & $\begin{array}{l}19(65.5 \%) \\
10(35.5 \%)\end{array}$ & $\begin{array}{l}20(60.6 \%) \\
13(39.4 \%)\end{array}$ & 0.89 \\
\hline $\begin{array}{l}\text { Child-Pugh grade } \\
\text { A } \\
\text { B / C } \\
\text { Child-Pugh score }\end{array}$ & $\begin{array}{c}3(10.3 \%) \\
12 / 14(89.7 \%) \\
8.9 \pm 1.6\end{array}$ & $\begin{array}{c}3(9.1 \%) \\
13 / 17(90.9 \%) \\
9.0 \pm 1.8\end{array}$ & $\begin{array}{l}0.89 \\
0.82\end{array}$ \\
\hline $\begin{array}{l}\text { MELD } \\
\text { Bilirubina (mg/dL) } \\
\text { INR }^{a} \\
\text { Creatinine }^{\mathrm{a}}(\mathrm{mg} / \mathrm{dL})\end{array}$ & $\begin{array}{l}10.9 \pm 4.0 \\
2.3 \pm 1.4 \\
1.5 \pm 0.2 \\
0.9 \pm 1.0\end{array}$ & $\begin{array}{l}13.2 \pm 7.0 \\
2.8 \pm 1.7 \\
1.7 \pm 0.5 \\
1.0 \pm 1.1\end{array}$ & $\begin{array}{l}0.12 \\
0.30 \\
0.14 \\
0.92\end{array}$ \\
\hline Ascites & $17(56.6 \%)$ & $16(48.5 \%)$ & 0.42 \\
\hline History of variceal bleeding & $16(55.2 \%)$ & $12(36.4 \%)$ & 0.13 \\
\hline Prophylactic treatment & $15(51.7 \%)$ & $10(30.3 \%)$ & 0.08 \\
\hline Hemoglobin $^{a}(\mathrm{~g} / \mathrm{dL})$ & $9.6 \pm 1.7$ & $9.4 \pm 2.9$ & 0.75 \\
\hline Active bleeding & $15(51.7 \%)$ & $16(48.5 \%)$ & 0.99 \\
\hline Shock & $6(20.7 \%)$ & $9(27.3 \%)$ & 0.54 \\
\hline Systolic blood pressure (mmHg) & $106 \pm 20$ & $113 \pm 28$ & 0.32 \\
\hline Diastolic blood pressure $(\mathrm{mmHg})$ & $58 \pm 13$ & $60 \pm 17$ & 0.61 \\
\hline Heart rate (bpm) & $91 \pm 17$ & $90 \pm 15$ & 0.84 \\
\hline $\begin{array}{l}\text { Variceal grade } \\
\qquad \text { |-I } \\
\text { III-IV }\end{array}$ & $\begin{array}{l}16(61.5 \%) \\
10(38.5 \%)\end{array}$ & $\begin{array}{l}13(48.1 \%) \\
14(51.9 \%)\end{array}$ & 0.24 \\
\hline Gastric varices & $3(10.3 \%)$ & $6(18.2 \%)$ & 0.30 \\
\hline Hepatocellular carcinoma & $2(6.9 \%)$ & $2(6.1 \%)$ & 0.64 \\
\hline Infection & $7(24.1 \%)$ & $4(12.1 \%)$ & 0.21 \\
\hline
\end{tabular}

rebleeding, as defined above, was more frequent in patients from group I than in patients from group II (35\% [10/29] vs. 15\% [5/33] respectively, $\mathrm{p}=0.06$; RR 0.4 [0.1-1.1]). Relative risk reduction attributable to treatment in exposed subjects (RRR) was $57 \%$, and NNT to avoid one episode of early rebleeding was 5 . As a consequence of these data, therapy efficacy was 66\% (19/29) and $82 \%$ (27/33) for patients included en groups I and II, respectively, $\mathrm{p}=0.12$; RR 1.2 [0.9-1.7].

Overall, 31 patients showed active bleeding at initial endoscopy (15 and 16 from groups I and II, respectively). The percentage of early rebleeding was significantly higher in patients with active bleeding at endoscopy than in patients without it (11 out of 31 vs. 4 out of 31, 36\% vs. 13\%, p = 0.03 by Chi-square test). Although early rebleeding was lower and efficacy was higher in patients with active bleeding that had been treated with dual therapy (group II), these differences did not reach statistical significance (Table II).

Twenty-six and 30 patients with advanced liver disease (Child-Pugh B or C) were included in groups I and II, respectively (Table I). The number of patients in which an initial control of bleeding was achieved was similar in both subgroups of patients. However, early rebleeding was significantly less frequent, and therapy efficacy was consequently higher, in patients included in group II (Table II). In Child-Pugh B or C patients, RRR by therapy was $67 \%$, and NNT to avoid one episode of early rebleeding was 4 .

Transfusion requirements and length of hospitalization were similar in both groups of patients (Table III).

\section{Adverse events related to treatment}

Endoscopic sclerotherapy was associated with thoracic pain or esophageal ulcers in 2 and 5 patients from groups

Table II. Control of bleeding in patients included in groups I and II. See definitions in text.

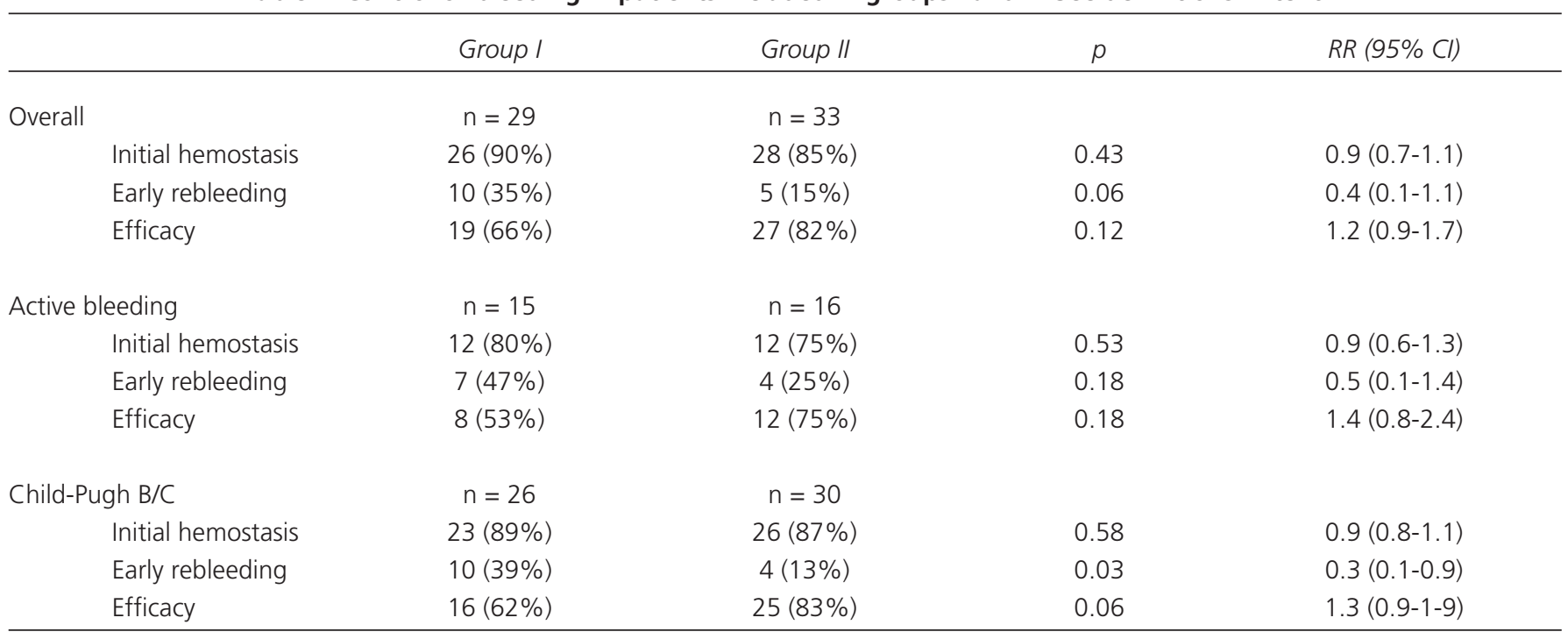


I and II, respectively (7 vs. 15\% p = 0.26; RR 2.1 [0.4$10.4])$. Eight patients from group I (28\%) and 17 patients from group II $(52 \%)$ developed hyperglycemia or nausea when being administered the SMT bolus $(\mathrm{p}=0.04$; RR 1.8 [0.9-3.6]. SMT had to be suspended in no patients because of side effects.

\section{Mortality}

No statistically significant differences were observed in mortality either during the study period or during a 6 weeks period after the bleeding episode (Table II) between both groups of patients. In group II, RR for early mortality was $0.6(0.1-2.7)$, and for 6-week mortality was $0.6(0.2-1.7)$. Respective death reasons in patients included in groups I and II were early rebleeding (4 and 3), rebleeding after study completion (0 and 2), and hepatorenal syndrome (1), pneumonia (1) and liver failure (1), all of them included in group I.

All 12 patients (19\%) who died during the study period had advanced liver disease (Child-Pugh C), with 7 in group I and 5 in group II, $\mathrm{p}=0.21$; RR 0.5 [0.2-1.4]. Considering only Child-Pugh C patients, 8 of the 12 patients who died during the study period showed active bleeding at endoscopy, $\mathrm{p}=0.49$; RR $1.6(0.6-4.3)$. Considering only Child-Pugh $\mathrm{C}$ patients, 8 of the 12 patients who died during the study period showed active bleeding at endoscopy, $\mathrm{p}=0.49$; RR $1.6(0.6-4.3)$. In these patients (Child-Pugh C) treatment efficacy has been associated with lower mortality $(67 \%$ [8/12] vs. $21 \%$ [4/19] $\mathrm{p}=$ 0.01 ; RR $0.3[0.1-0.8]$ ). RRR of mortality attributable to treatment efficacy was $68 \%$, and NNT with efficacy to avoid one episode of death was 2.

Table III. Outcomes in patients included in groups I and II. See definitions in text

\begin{tabular}{lccc}
\hline & $\begin{array}{c}\text { Group I } \\
n=29\end{array}$ & $\begin{array}{c}\text { Group II } \\
n=33\end{array}$ & $p$ \\
\hline Transfusion requirements & $3.4 \pm 1.5$ & $3.9 \pm 3.5$ & 0.91 \\
Days of hospitalization & $13.2 \pm 7.7$ & $11.1 \pm 6.9$ & 0.27 \\
Early mortality & $4(14 \%)$ & $3(9 \%)$ & 0.42 \\
Six-week mortality & $7(24 \%)$ & $5(15 \%)$ & 0.47 \\
\hline
\end{tabular}

\section{DISCUSSION}

In this prospective, randomized controlled trial, we show that the perfusion of SMT $500 \mu \mathrm{g} / \mathrm{h}$ in association with emergency sclerotherapy in patients with cirrhosis (Child-Pugh B or C) and esophageal hemorrhage significantly decreases early rebleeding rates.

The development of esophageal variceal bleeding is a severe complication arising in patients with advanced cirrho- sis, and requires urgent therapeutic endoscopy (3). Since a decrease in variceal pressure may facilitate bleeding control, an association of pharmacological therapy with urgent endoscopic sclerotherapy has been suggested to improve the overall efficacy of treatment. Until 1998 six different studies published as full papers or in abstract form has addressed this possibility (15-20), and suggested a higher efficacy of combined therapy over sclerotherapy alone in the control of bleeding episodes and for decreasing rebleeding rates (21), Also, the addition of sclerotherapy to SMT has been shown to be more efficacious than SMT alone (22). We therefore designed this prospective, randomized trial to compare the efficacy of two different dosages of SMT (250 vs. $500 \mu \mathrm{g} / \mathrm{h}$ ) associated with emergency endoscopic sclerotherapy in patients with esophageal variceal bleeding. In accordance with our hypothesis a recently published metaanalysis has raised similar conclusions (23).

Bleeding episode control after emergency endoscopy was above $84 \%$ in the overall group of patients, being similar in both treatment groups, and also similar to the corresponding figure reported in previously published trials $(17,24,25)$. While all patients received a bolus of SMT before emergency endoscopy, active bleeding was seen in half of patients included in the study, and initial hemostasis was achieved in these patients in a percentage similar to that previously reported (26). Also, the percentage of patients showing absence of active bleeding at initial endoscopy was similar to that reported before in patients without previous therapeutic maneuvers (27). It seems likely that the administration of SMT prior to endoscopy decreases bleeding, thus facilitating endoscopic treatment (15). However, in this study a bolus of SMT $(500 \mu \mathrm{g})$ did not modify the proportion of patients achieving initial hemostasis after endoscopy.

In this study the proportion of Child $\mathrm{B}$ or $\mathrm{C}$ patients is high, and this is likely due to the fact that our Bleeding Unit admits serious active bleeders from other hospitals. A posthoc analysis showed that the incidence of early rebleeding was significantly lower in Child-Pugh B or C patients included in group II vs. similar patients from group I (13 vs. $39 \%$, respectively, $\mathrm{p}=0.03$ ). According to our data, $4 \mathrm{pa}-$ tients with advanced liver disease are needed to undergo treatment with the $500 \mu \mathrm{g} / \mathrm{h}$ dose in order to avoid one episode of early rebleeding, and this therapy reduced the risk of early rebleeding by $67 \%$ in comparison with patients of group I. When considering the overall group of patients, the incidence of early rebleeding was near the significance level (35\% group I vs. $15 \%$ group II, $\mathrm{p}=0.06$ ), and this percentage $(15 \%)$ was lower than that reported in previous studies, comparing the usual SMT $250 \mu \mathrm{g} / \mathrm{h}$ dosage associated with endoscopic therapy $(17,20)$. It is likely that this benefit is related to a greater decrease in portal pressure gradient, since it has been recently shown that $57 \%$ of patients with variceal bleeding initially treated with a $250 \mu \mathrm{g} / \mathrm{h}$ dosage of SMT show a significant decrease of portal pressure gradient when the dose of SMT is increased to $500 \mu \mathrm{g} / \mathrm{h}$ (30). Since SMT is less effective during the acute episode of esophageal hemor- 
rhage than in patients with a stable clinical condition (29), it may be useful to use a higher SMT dosage in circumstances associated with a higher portal pressure, such as active bleeding (30), or in patients with more advanced liver disease (31), as suggested by our data.

Overall, 12 patients died (19\%), of which 7 died during the first 5 days of therapy. Sixty-seven percent of the patients who died had shown acute variceal bleeding at inclusion in the study, and all belonged to Child-Pugh class $\mathrm{C}$. It has been previously reported that liver function is the most important factor for survival in patients with variceal bleeding $(15,32,33)$. Obviously, there was a significant relation between mortality and lack of treatment efficacy. Finally, this study confirms the good tolerance of SMT when used at a $500 \mu \mathrm{g} / \mathrm{h}$ dosage.

In conclusion, this prospective and randomized study shows that the perfusion of SMT $500 \mu \mathrm{g} / \mathrm{h}$ in association with emergency sclerotherapy in patients with cirrhosis and esophageal hemorrhage is a well tolerated treatment that significantly decreases the rate of early rebleeding in patients with more advanced liver disease.

\section{REFERENCES}

1. Berzogotti A, García-Pagán JC, Bosch J. Therapy of acute variceal bleeding. In: Arroyo V, Bosch J, Bruix J, Ginés P, Navasa M, Rodés J, editors. Therapy in Hepatology. Barcelona: Ars Medica, 2001. p. 3-16.

2. Soriano G, Guarner C, Tomas A, Villanueva C, Torras X, González $\mathrm{D}$, et al. Norfloxacin prevents bacterial infection in cirrhotics with gastrointestinal hemorrhage. Gastroenterology 1992; 103: 1267-72.

3. De Franchis R. Evolving consensus in portal hypertension. Report of the Baveno IV consensus workshop in portal hypertension. J Hepatol 2005; 43: 167-76.

4. Tyden G, Sammergard H, Thulin L, Friman L, Efendic S. Treatment of bleeding esophageal varices with somatostatin. N Engl J Med 1978; 299: 1466-7.

5. Bosch J, Kravetz D, Rodes J. Effects of somatostatin on hepatic and systemic hemodynamics in patients with cirrhosis of the liver: comparison with vasopressin. Gastroenterology 1981; 11: 13-21.

6. Villanueva C, Ortiz J, Miñana J, Soriano G, Sabat M, Boadas J, et al. Somatostatin treatment and risk stratification by continuous portal pressure monitoring during acute varicela bleeding 2001; 121: 110-7.

7. Cirera I, Feu F, Luca A, García-Pagán JC, Fernández M, Escorsell A, et al. Effects of bolus injections and continuous infusions of somatostatin and placebo in patients with cirrosis: A double-blind hemodynamic investigation. Hepatology 1995; 22: 106-11.

8. Nevens F, Sprengers D, Fevery J. The effect of different doses of a bolus injection of somatostatin combined with a slow infusion on transmural oesophageal variceal pressure in patients with cirrhosis. J Hepatol 1994; 20: 27-31.

9. Goulis J, Burroughs AK. Portal hypertensive bleeding: prevention and treatment. En: McDonald J, Burroughs A, Feagan B, editors. Evidence based gastroenterology and hepatology. London: BMJ Books; 1999. p. 389-426.

10. Abraldes JG, Bosch J. Somatostatin and analogues in portal hypertension. Hepatology 2002; 35: 1305-12.

11. Moitinho E, Planas R, Bañares R, Albillos A, Ruiz del Árbol L, Gálvez C, et al. Variceal Bleeding Study Group. Multicenter randomized controlled trial comparing different schedules in the treatment of acute variceal bleeding. J Hepatol 2001; 35: 712-8.

12. Avgerinos A, Viazis N, Vlachogiannakos J, Polianos G, Armonis A, Manolakopoulos S, et al. Two different doses and duration of patients with bleeding oesophageal varices: a non-randomised controlled study. J Hepatol 2000; 32: 171-4.

13. Bass NM, Yao FY. Portal Hipertension and Variceal Bleeding. En:
Feldman F, Friedman LS, Sleisenger MH, editors. Gastrointestinal and Liver Disease. Philadelphia: Saunders; 2002. p. 1487-516.

14. Arroyo V, Gines P, Gerbes AL, Dudley FJ, Gentilini P, Laffi G, et al. Definition and diagnosis criteria of refractory ascites and hepatorenal syndrome in cirrhosis. International Ascites Club. Hepatology 1996; 23 (1): $164-76$

15. Avgerinos A, Nevens F, Raptis S, Fevery J and the ABOVE Study Group. Early administration of somatostatin and efficacy of sclerotherapy in acute oesophageal variceal bleeds: the European Acute Bleeding Oesophageal Variceal Episodes (ABOVE) randomised trial. Lancet 1997; 350: 1495-9.

16. Sung JJ, Chung SC, Yung MY, Lai CW, Lau JY, Lee YT, et al. Prospective randomised study of effect of octreotide on rebleeding from oesophageal varices after endoscopic ligation. Lancet 1995; 346: 1666-9.

17. Besson I, Ingrand P, Person B, Boutroux D, Heresbach D, Bernard P, et al. Sclerotherapy with or without octreotide for acute variceal bleeding. N Engl J Med 1995; 333: 550-60.

18. Signorelli S, Negrini F, Paris B, Bonelli M, Girolla M. Sclerotherapy with or without somatostatin or octreotide in the treatment of acute variceal haemorrhage: our experience (Abstract). Gastroenterology; 1996: 110: 1326A.

19. Ceriani R, Curioni R, Moroni L, Repaci G, Brunati S. Scleroteraphy alone (ES) vs. sclerotherapy plus terlipressin (EST) vs. sclerotherapy plus octreotide (ESO) in the treatment of acute variceal bleeding (Abstract). Gastroenterology 1997; 112: 1238A.

20. Signorelli S, Paris B, Negrini F, Bonelli M, Auriemma L. Esophageal varices bleeding: comparison between treatment with sclerotherapy alone vs. sclerotherapy plus octreotide (Abstract). Hepatology 1997; 26: 137A.

21. De Franchis R, Primignani M. Endoscopic treatments for portal hipertension. Semin Liver Dis 1999; 19: 439-55.

22. Villanueva C, Ortiz J, Sabat M, Gallego A, Torras X, Soriano G, et al. Somatostatin alone or combined with emergency in the treatment of acute variceal bleeding: a prospective randomized trial. Hepatology 1999; 30: 384-9.

23. Bañares R, Albillos A, Rincón D, Alonso S, González M, Ruiz del Árbol L, et al. Endoscopic treatment versus endoscopic plus pharmacologic treatment for acute variceal bleeding: a meta-analysis. Hepatology 2002; 35: 609-15.

24. Westaby D, Hayes PC, Gimson AE, Polson RJ Williams R. Controlled clinical trial of injection sclerotherapy for active variceal bleeding. Hepatology 1989; 9: 274-7.

25. Sung JJ, Chung SC, Lai CW, Chan FK, Leung JW, Yung MY, et al. Octreotide infusion or emergency sclerotherapy for variceal haemorrhage. Lancet 1993; 342: 637-41.

26. Gross M, Schiemann U, Mülhöfer A, Zoller WG. Meta-analysis: efficacy of therapeutic regimens in ongoing variceal bleeding. Endoscopy 2001; 33: 737-46.

27. Luketic VA, Sanyal AJ. Esophageal varices. I Clinical presentation, medical therapy and endoscopy therapy. En: Capell MS, editors. High Risk Gastrointestinal Bleeding, Part II. Gastroenterol Clin North Am 2000; 29: 337-85.

28. Aracil C, Planella M, López-Balaguer JM, Monfort D, Piqueras M, Fort E, et al. Efectos hemodinámicos de glipressina y dosis altas de somatostatina durante el episodio agudo de hemorragia por varices esofágicas (abstr). Gastroenterol y Hepatol 2003; 26: 76.

29. Moitinho E, Escorsell A, Bandi JC, García-Pagán JC, Castañeda B, Andreu V, et al. Somatostatin is less effective decreasing portal pressure during acute variceal bleeding than in stable conditions (abstr). J Hepatol 1998; 28: 74.

30. Moitinho E, Escorsell A, Bandi JC, Salmeron JM, García-Pagán JC, Rodes J, et al. Prognostic value of early measurements of portal pressure in acute variceal bleeding. Gastroenterology 1999; 117: 626-31.

31. Match D, Armonis A, Sabin K, Christopoulou K, Greenslade L, McCormick A, et al. Single portal pressure measurement predicts survival in cirrhotic patients with recent bleeding. Gut 1999; 44: 264-9.

32. Burroughs AK, McCormick A, Hughes MD, Sprengers D, D'Heyghere F, McIntyre N. Randomized, double blind, placebo-controlled trial of somatostatin for acute variceal bleeding emergency control and prevention of early variceal bleeding. Gastroenterology 1990; 99: 1388-95.

33. Feu F, Ruiz del Árbol L, Bañares R, Planas R, Bosch J, and members of the Variceal Bleeding Study Group. Double-blind randomized controlled trial comparing terlipressin and somatostatin for acute variceal hemorrhage. Gastroenterology 1996; 111: 1291-9. 